\title{
Design and Development of Automated Irrigation System
}

\author{
Arjunsing T. Rathod ${ }^{1}$, Dr. A. U. Awate ${ }^{2}$ \\ ${ }^{1}$ M.E. CAD/CAM, Scholar, ${ }^{2}$ Professor, Department of Mechanical Engineering \\ Prof. Ram Meghe Institute of Technology and Research, Badnera, Maharashtra, India
}

\begin{abstract}
In India, agriculture plays an important role for development in food production. In our country, agriculture are depends on the monsoons which is not sufficient source of water. So the irrigation is used in agriculture field. The greenhouse based modern agriculture industries are the recent requirement in every part of agriculture in India. In this technology, The overhead structure is created for the movement of water spraying machine. This machine unit which is programmed by the microcontroller will spray the water from start to end plant in the rows. This system provides the equal amount of water to every plant in the greenhouse unit. One of the objectives of this work is to see how human control could be removed from irrigation and also to optimize the use of water in the process. In greenhouse effect it is very difficult to provide adequate amount of water by manual watering process Hence, Automated irrigation system plays an important role. It also helps in time saving, removal of human agriculture and the climatic conditions. The most important factor of this system is microcontroller is used to control the movement of water spraying machine.
\end{abstract}

Key Words: Automation, Overhead structure, Microcontroller, Water spraying machine, Soil moisture sensor

\section{INTRODUCTION}

Continuous increasing demand of food requires the control in highly specialized greenhouse vegetable rapid improvement in food production technology. In a production and it is a simple, precise method for country like India, where the economy is mainly based on irrigation. The irrigation system provide only required amount of water to crop. This automated irrigation system allows it to be scaled up for larger greenhouses or open fields. An automated irrigation system was developed to optimize water use for agricultural crops. Agriculture is the main source for food production. Using science and technology we need to implement a method by which there can be limited consumption of water source is needed. The green house based modern agriculture industries are the recent requirement in every part of agriculture in India. In this technology, the humidity and temperature of plants are precisely controlled. In greenhouse effect plants are planted very nearer to each other so it is very difficult to give adequate amount of water to all plants. Manual watering process is not so easy for every plant in the greenhouse effect, so the different types of irrigation systems are developed like Surface irrigation, Drip irrigation, Sprinkler irrigation, Centre pivot irrigation, Lateral move irrigation, Sub-irrigation and manual irrigation. In this project overhead structure is provided for the plant watering process. One water spraying device is located on the overhead structure which will operate by the use of microcontroller. The water spraying element is programmed in such a way that it will follow the instruction given by the microcontroller. It will spray the adequate amount of water to each plant in the greenhouse effect. This type of technology is more efficient use of water for irrigation in agriculture.

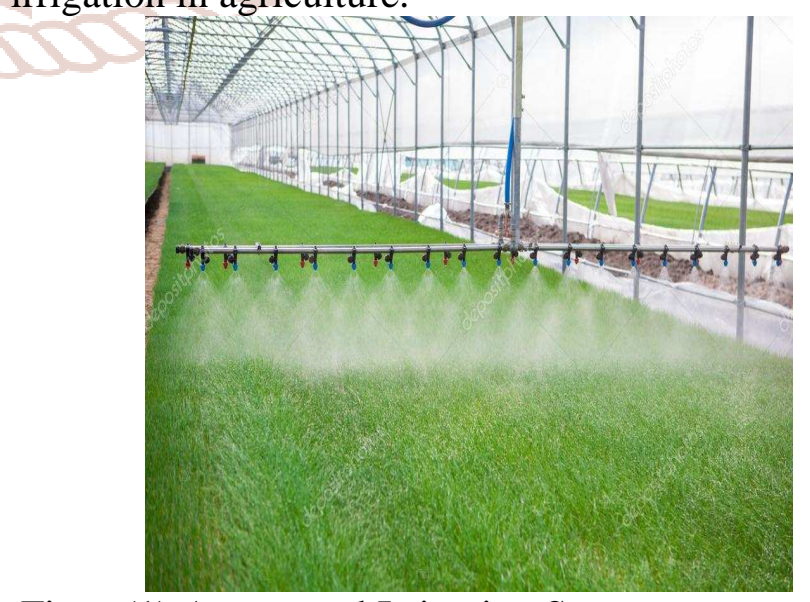

Fig :- (1) Automated Irrigation System 


\section{SOIL MOISTURE SENSOR}

Water is a very precious resource and a driving force in irrigation. Adequate amount of water is needed to every plant in the field, getting better plant yields, reduce dependency on fertilizers and improve crop quality. Various methods are available to measure soil moisture content, but the quickest and better one is with the use of soil moisture sensor electronic devices. For successful irrigation, it is necessary to monitor soil moisture content continuously in the irrigation fields. This sensor can be used to test the moisture of soil, When the soil is having water shortage, the sensor will show the moisture content on LED display and microcontroller will perform the operation.

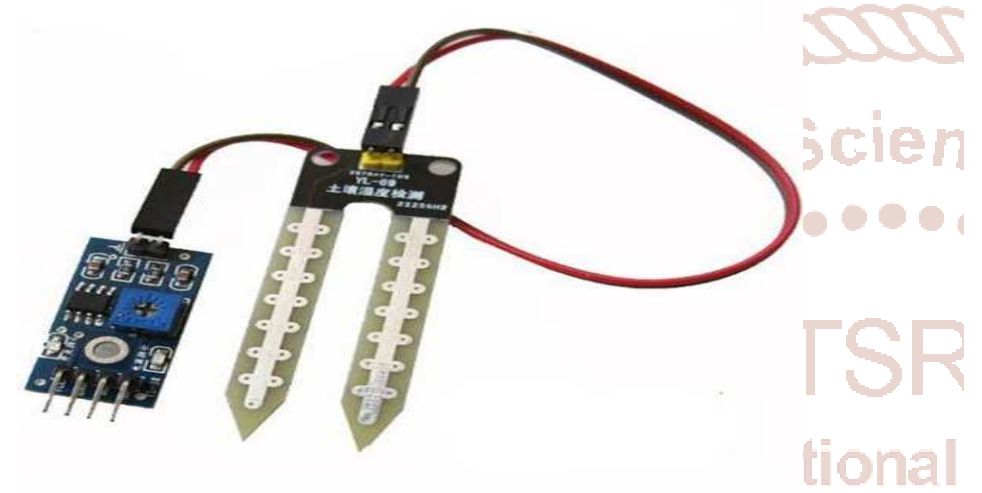

Fig :- (2) Soil Moisture Sensor

Soil moisture sensors measure the water content in soil. A soil moisture probe is made up of multiple soil moisture sensors. One common type of soil moisture sensors in commercial use is a Frequency domain sensor such as a capacitance sensor. Another sensor, the neutron moisture gauge, utilize the moderator properties of water for neutrons. Soil moisture content may be determined via its effect on dielectric constant by measuring the capacitance between two electrodes implanted in the soil.

\section{METHODOLOGY}

The Microcontroller based automated irrigation system consists of moisture sensor, microcontroller, Relay driver, DC motors, overhead moving system etc. The moisture sensor is buried in the field at required depth. If the moisture content in the field gets reduced to lower threshold limit, the signal is produced from the microcontroller to turn ON relay. The relay allowed overhead moving system to reach over to each plant and spray water over it from the source is supplied to the field. Moisture level sensed from the sensor will be displayed in the LCD display. After reaching upper threshold limit, the sensor gives corresponding signal to the microcontroller and the relay is turned OFF.

\section{BLOCK DIAGRAM}

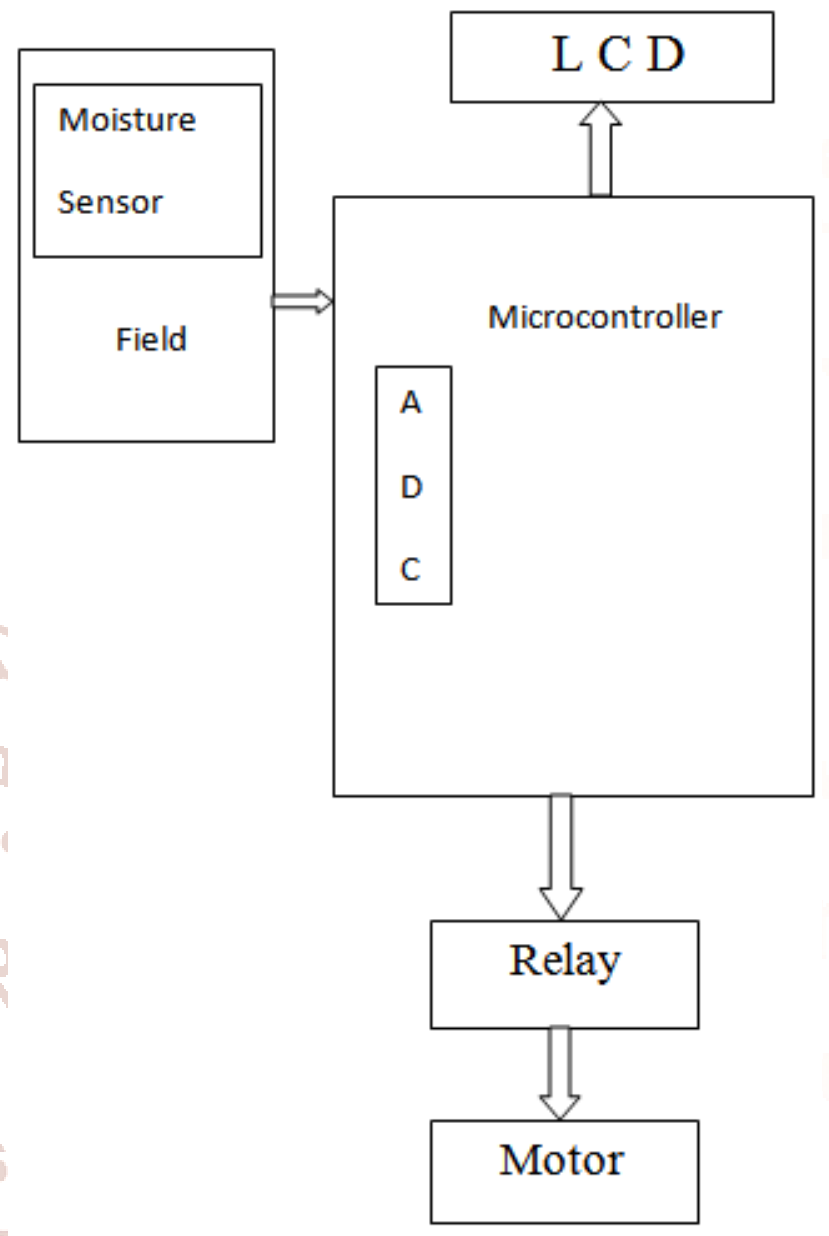

Fig :- (3) Block Diagram of Microcontroller Based Automated Irrigation System

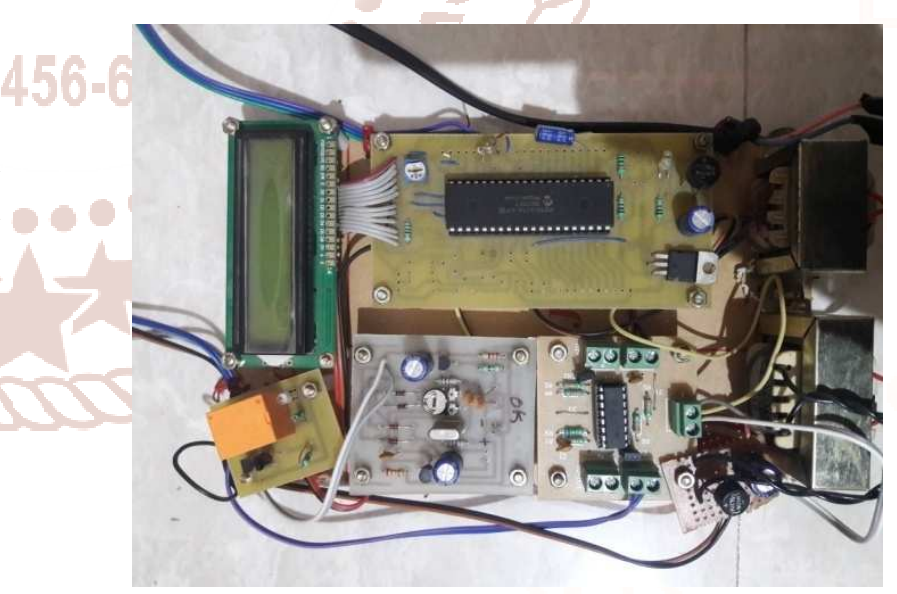

Fig :- (3) Electronic Circuit

This circuit includes Relay, Micro chip, LED display screen, Transformers, Soil moisture sensor circuit, Water spraying circuit

1. Relay: This unit takes signal from the microcontroller and provides output signal to the water spraying motor.

2. Microcontroller: This unit provides movement of the overhead system forward and backward motion is done by the signal of microcontroller. 
3. LED Display: LED display shows the soil moisture contents, If soil moisture is low then water spraying motor will start and water will come from the nozzle until the soil moisture level come up to 45 after that system stops.

4. Soil Moisture Sensor Circuit: This circuit detects the soil moisture level and send signal to the motor via relay.

5. Water Spraying Circuit: This motor run when soil moisture level below 45 until it comes to the 45 till that limit water will be continuously sprayed.

6. Transformer: Transformers are provided for the change of voltage in the circuit. This system requires $12 \mathrm{~V}$ DC supply which we can provide from the battery but the battery cannot provide same supply for long period of time so we need to charge it again and again instead of that we have used AC supply which is converted in to DC by Transformers.

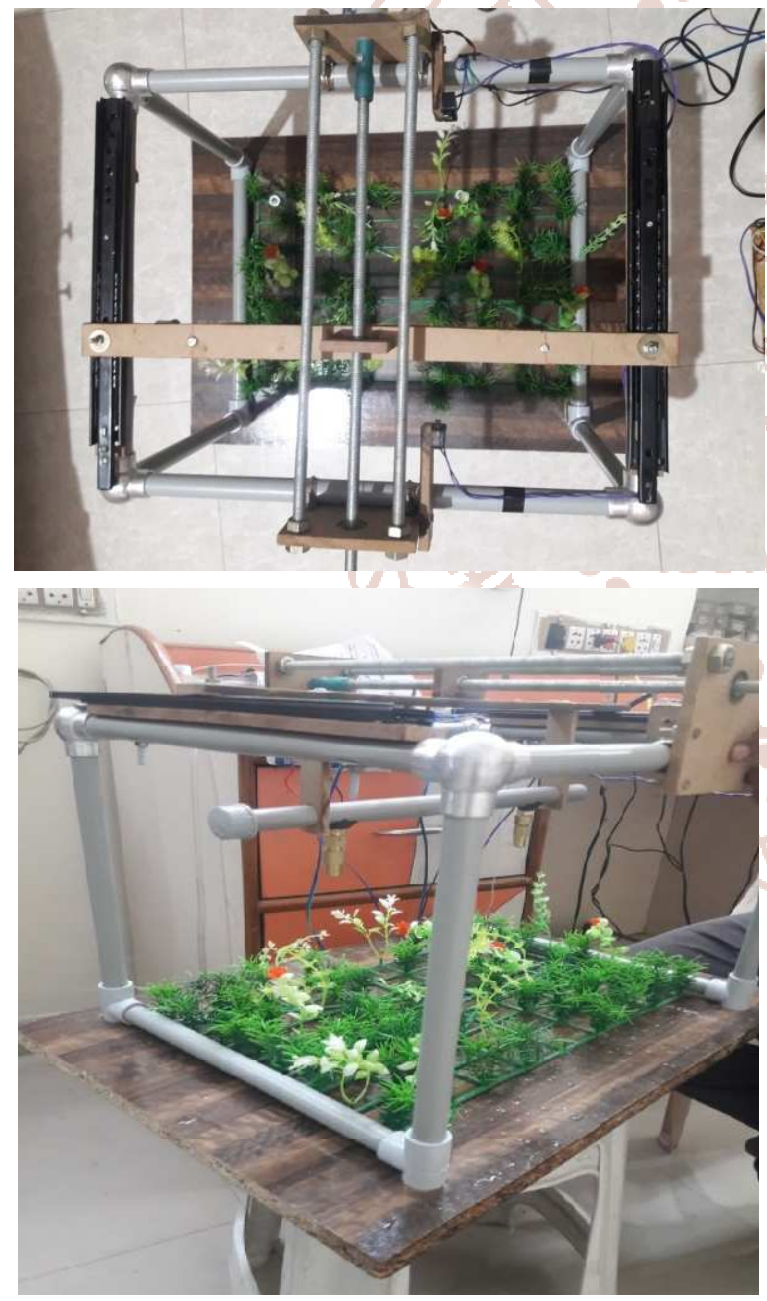

Fig :- (4) Automated Irrigation System

In this model we have used one plywood sheet which is called base on that base we have mounted four vertical pvc pipes for support structure. Artificial plants are implanted for better look. Two channels are provided for the movement of horizontal slider which perform forward and backward movement of spraying nozzles. One DC motor of 200 RPM used for the movement of slider with the help of long threaded rod of $10 \mathrm{~mm}$ diameter. Two medium density fiber board (MDF) which are used for supportive structure of dimension $100 \mathrm{~mm} * 100 \mathrm{~mm}$, At one side DC motor is fixed with threaded stud and fixed at the another end. Two threaded studs are fixed at both MDF sheet with the help of nuts. One horizontal pvc pipe is fixed in between two vertical slide of MDF sheet. On that horizontal pvc pipe two nozzles are provided for spraying unit. Two limit switches are provide at both sides for the slider so that it will not cross the limit when it perform forward and backward motion.

\section{CATIA DESIGN}

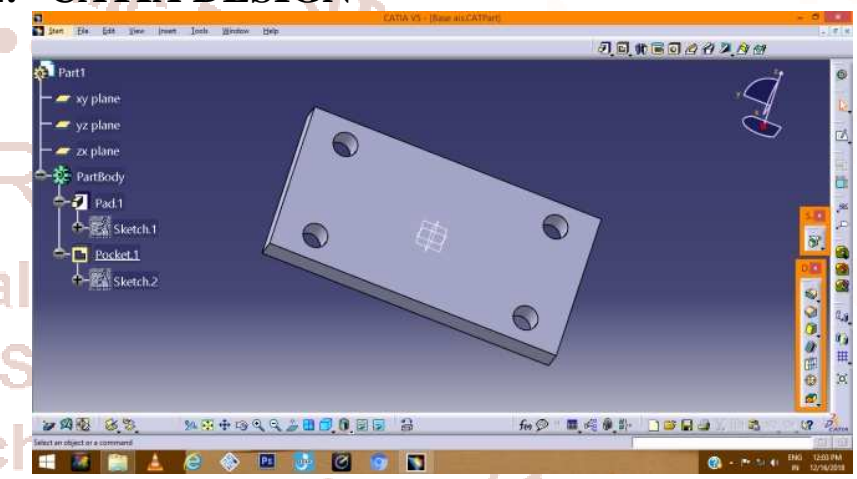

Fig :- (5) Plywood Base

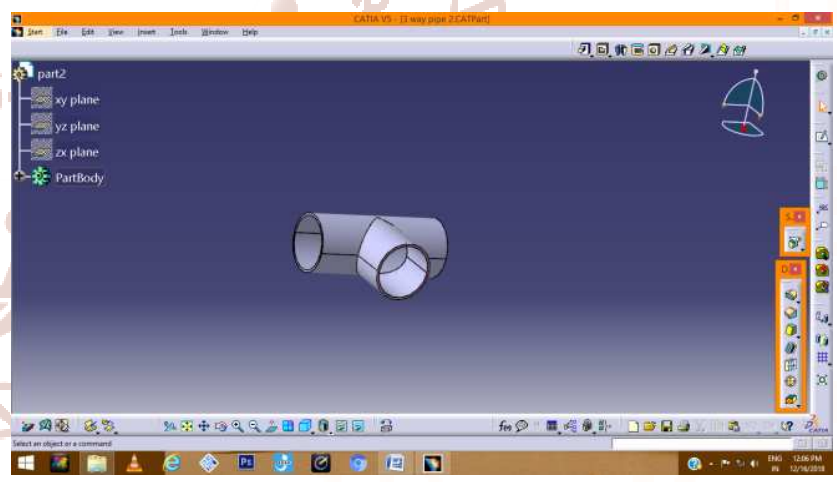

Fig :- (6) T PVC Pipe

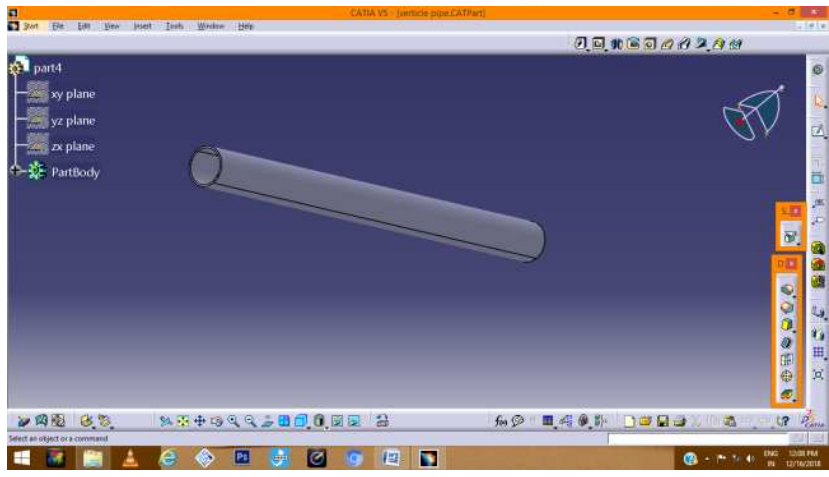

Fig :- (7) Vertical Pipes 


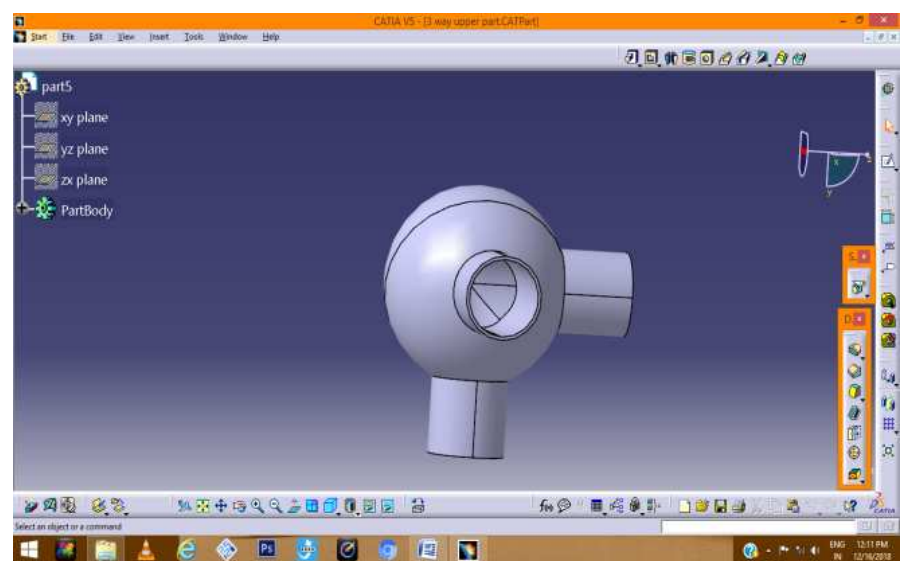

Fig :- (8) 3 Way Upper Joint

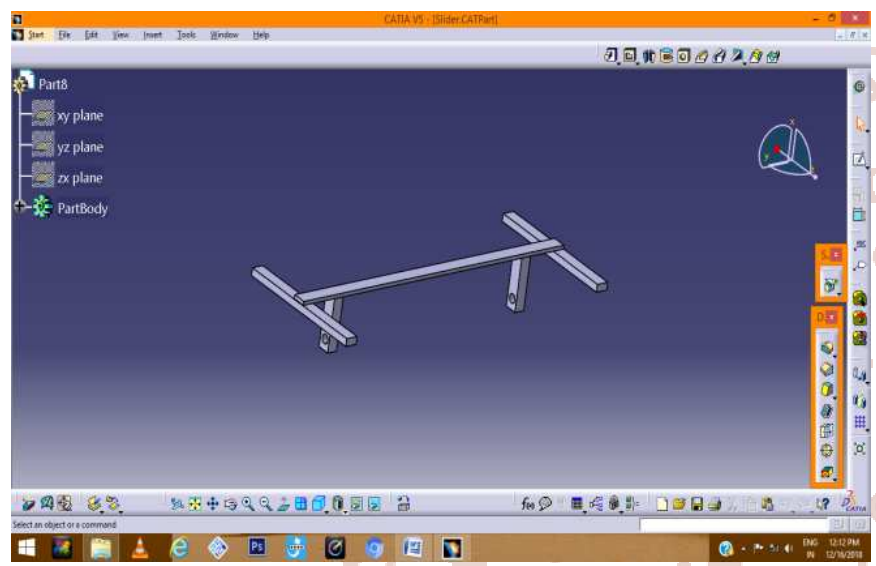

Fig :- (9) Slider

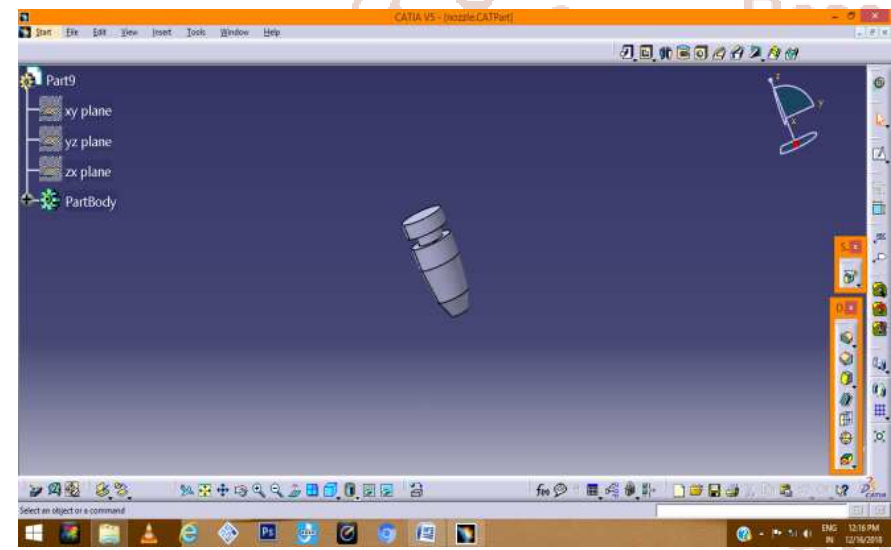

Fig :- (10) Nozzle

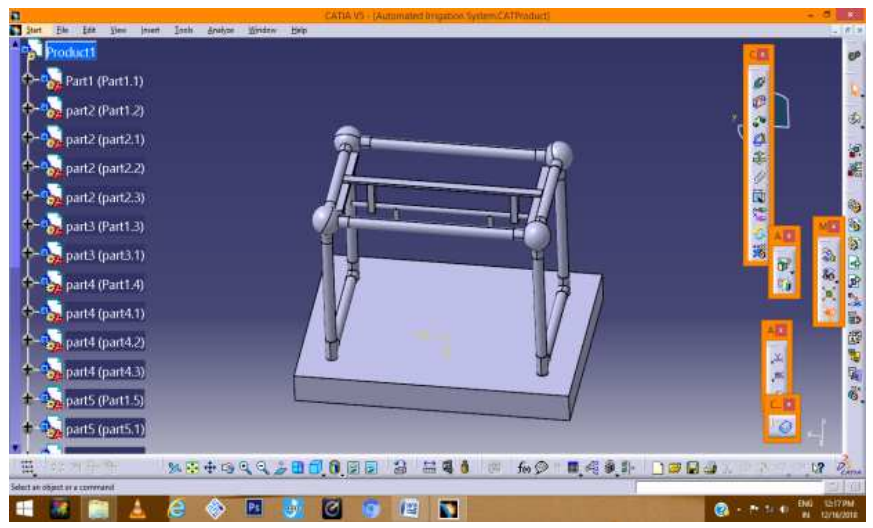

Fig :- (11) Automated Irrigation System

\section{ADVANTAGES}

The smart irrigation system will help us to provide significant amount of water to every plant in the greenhouse effect. It helps us to reduce human efforts for manual watering process. It improves the yields of crops which mean more income for the farmer people prosperous. Soil moisture sensors are more accurate than rain sensors because they can detect moisture at the level of the root system. They are more exact in measuring how much water your plants are receiving and thus offer greater water savings.

\section{APPLICATIONS}

An overhead watering method is a practical choice to cover all the pots evenly with moisture. Sprinkler heads connected to overhead water pipes emit a misty spray across the entire greenhouse. Larger greenhouses benefit from this irrigation method because the sprinklers cover a significant amount of square footage in a short amount of time. This system is designed to apply water by moving over the plants. Using boom irrigation facilitates uniform water application which in turn results in healthy growth of the plants. Due to easy operation, uniformity and efficiency, boom irrigation system are estimated to register strong growth over the forecast period.

\section{FUTURE SCOPE}

In this system we can provide reverse watering process by programming method. Overhead system works on the basis of microcontroller device. We can implant outside temperature and humidity sensor. Whenever there is a change in temperature and humidity of the surroundings these sensors sense the change in temperature and humidity of the surroundings and gives an interrupt signal to the microcontroller. If different kinds of sensors (that is, temperature, humidity, and etc.) are involved in such irrigation in future work, it can be said that an internet based remote control of irrigation automation will be possible.

\section{CONCLUSION}

The primary application of this project is for farmers and gardeners who do not have enough time to water their Crops/plants. The system improves the efficiency of water use to save water, relying on modern science and technology to achieve high quality and crop yield with the littlest water source. The Microcontroller based overhead irrigation system proves to be real time feedback control system which 
monitors and controls all the activities of overhead irrigation system efficiently.

\section{REFRENCES}

1. R. Vagulabranam, M. Karthikeyan, V. Sasikala, "Automatic Irrigation System On Sensing Soil Moisture Content" International Research Journal Of Engineering \& Technology (IRJET) ISSN: 2395-0056

2. Prof. Rashmi Jain, Shaunak Kulkarni, Ahtesham Shaikh, Akash Sood, " Automatic Irrigation System For Agriculture Field Using Wireless Sensor Network", International Research Journal Of Engineering \& Technology (IRJET) ISSN: 2395-0056

3. Anita K [3], “ Automatic Irrigation System" $2^{\text {nd }}$ International Conference on "Innovative Trends in Science, Engineering and Management" ISBN: 978-93-86171-10-8

4. Bikash Chandra Saha, Avinash Kumar, Naiyer Mumtaz, [4] " Microcontroller Based Irrigation System Of Sensing Soil Moisture"
5. Shagun Agrawal, Suyash Pandey, Shravan Kumar, Kunal Chaudhery, " Automatic Irrigation System" International Journal of Advance Researchand Innovation, Volume 2, Issue 1(2014) 92-94 ISSN 2347-3258

6. Abhishek Kumar, Mangesh. S, “ Automated Irrigation System Based On Soil Moisture Using Arduino" International Journal of Pure and Applied Mathematics Volume 116 No.21 2017, 319-323

7. Priyamitra Munoth, Rohit Goyal, Kuldeep Tiwari, "Sensor based Irrigation System", International Journal of Engineering Research \& Technology( IJERT) NCACE- 2016

8. Ms. Deweshvree Rane, Prof. P. R. Indurkar, Prof. D. M. Khatri, "REVIEW PAPER BASED ON AUTOMATIC IRRIGATION SYSTEM BASED ON RF MODULE”, IJAICT Volume 1, Issue9, January 2015

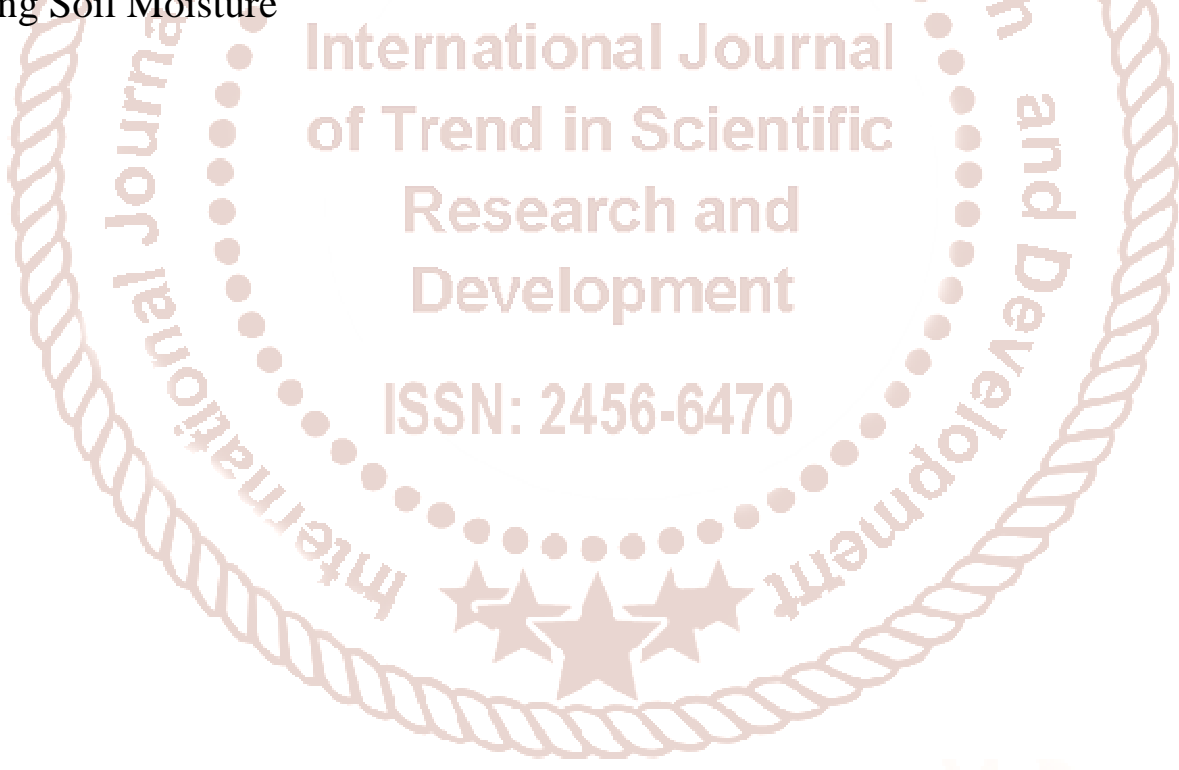

